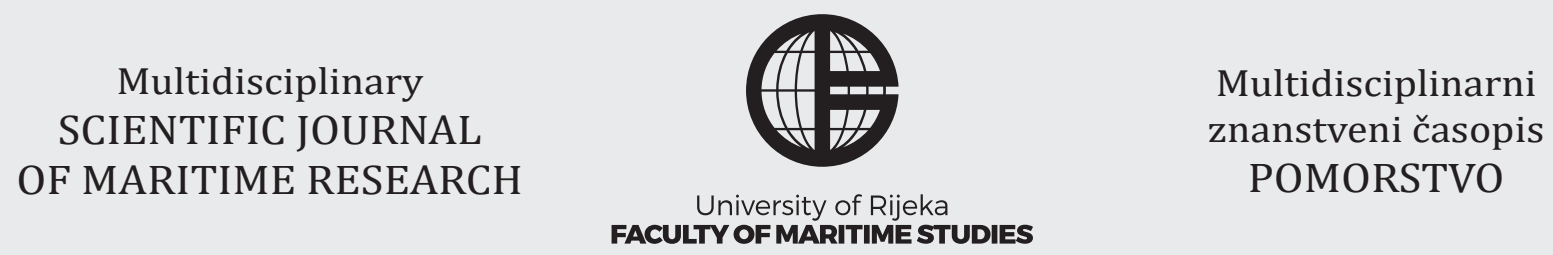

https://doi.org/10.31217/p.33.1.12

\title{
Comparative analysis of natural gas imports by pipelines and FSRU terminals
}

\author{
Filip Jovanović, Igor Rudan, Srđan Žuškin, Matthew Sumner \\ University of Rijeka, Faculty of Maritime Studies, Studentska 2, 51000 Rijeka, Croatia, e-mail: rudan@pfri.hr, szuskin@pfri.hr
}

\section{ABSTRACT}

Natural gas is one of the most sought-after trade commodities in the energy market, mainly due to exploitation of cleaner and sustainable energy sources. The most common transportation method for natural gas imports is either through designated pipelines in its gaseous state or carried in its liquefied state as Liquefied Natural Gas (LNG) by specialized tankers. The analysis and comparison of natural gas import by pipelines and FSRU (Floating Storage and Regasification Unit) terminals is presented in this paper. Pipeline import is currently the cheapest and most feasible option, but it requires significant infrastructural investments, which can affect imports in countries where production is far from the delivery, so alternatively vessels and import terminals are necessary to ensure natural gas imports and energy supply stability. This paper analyses the technology and current market outlook of both natural gas import methods.

\section{ARTICLE INFO}

\section{Review article}

Received 2 May 2019

Accepted 20 May 2019

Key words:

FSRU terminal

LNG

Gas pipelines

Energy imports

\section{Introduction}

In today's world, industries and households largely depend on energy sources. Fossil fuels have been in use for a long time, and now there is a process of replacing oil with alternative and more sustainable sources such is natural gas. Natural gas is considered as one of the cleanest fossil fuels due to the comprehensive purification processes after extraction. Considering continuous updates on available reserves, natural gas imports are currently profitable and largely available. Once the natural gas has been extracted, there are two choices of delivering the energy source to the end consumer, either by pipelines or by liquefying the natural gas to allow for shipment by sea. Shipping by pipelines is better choice for shorter distances and countries where population is scattered over larger areas. For the transport by tankers, natural gas is liquefied and delivered to the import terminal where it is brought back to its gaseous state. For this reason, both export and import terminals are required, which presents significant investment that has to be justified by economies of scale where infrastructure for natural gas already exists, or the focus will be on economies of scope where large industrial complexes are present in the vicinity of the import terminals. As the market for the natural gas is growing, there is a large demand for new LNG tankers, which is not yet fulfilled. This article presents a review of the current import processes and it is evident that still the pipeline imports are leading in numbers, however in a short run overseas supplies are going to change these numbers and real outlook will be evident in the decade to come. Considering the disruption of the natural gas import market, the scope of this review is to analyze FSRU terminals as special case of the import technology and compare it with pipeline imports.

\section{Overview of natural gas pipeline and FSRU terminal operations}

Natural gas demand is rising lately due to stricter emissions regulation, decentralization of production, cheaper prices than oil products, decreased scarcity while searching for alternative to OPEC driven prices, but also by general feel among citizens that globally cleaner energy sources is require. The main selection criteria for the method of transportation to the final consumer are heavily dependent on the distance from production and available infra- 
structure. Countries with densely populated consumers near the coastline will prefer sea transport, while countries with more scattered population inlands will have to invest in land infrastructure and will seek solutions from production sites closer to the consumers. Even though pipeline imports are cheaper, infrastructure development can require many years. The technology of natural gas pipelines is simpler than technology related to the sea transport and FSRU terminals. However, the economy of scale and economy of scope plays largest role in determining if the investment in certain technology will reach desired returns.

\subsection{Natural gas pipelines}

Imports by natural gas pipelines are simple and straightforward. Installation of natural gas pipelines from production site to the consumer is required, after which natural gas is supplied immediately. One of the main characteristics of the natural gas pipeline is the long-term investment, since its construction is not cost-effective in the short run, so it is commonly built after careful evaluation of the future demand (e.g. Russia - EU) [1]. But natural gas pipelines do not have any flexibility in case of altered demand. Consequently, there are no alternatives in case of pipeline failures, so final consumers can experience prolonged supply interruptions.

\subsubsection{Gas pipelines in general}

Natural gas pipelines could be classified into several categories. The first classification is based on the maximum permissible working pressure; therefore, exist low pressure pipelines (up to 0.1 bar), medium pressure pipelines (from 0.1 to 4.0 bar) and high pressure pipelines (from 4.0 to 100.0 bar), which besides for the gas transportation can also serve for natural gas storage [2]. The second classification differentiates natural gas pipelines according to their purpose, and these are main gas pipelines for the natural gas transport from production sites to large consumers (e.g. large gas supply companies) and distribution pipelines, which simultaneously supply a large number of smaller consumers (e.g. the city gas supply network) [2]. The third classification refers to spatial arrangement, i.e. the pipe lying, so there are overhead, underground and underwater gas pipelines. Underground pipelines are today the most common construction and are located at a minimum of 0.6 meters and a maximum of 2 meters below the ground for safety reasons to prevent freezing [3]. When choosing the pipeline route, it is important to pay attention to the safe distance from the existing overhead and underground infrastructure.

Natural gas pipeline construction sites have to allow for simple and quick gas pipeline access in case of regular maintenance and repairs. In the case of crossing over a river or watercourse, the underground gas pipeline goes shortly to the overhead, and is built on its own bridge constructions or on the existing bridges. Today, the maximum admissible lengths of land pipelines are up to $4000 \mathrm{~km}$ and underwa- ter up to $2000 \mathrm{~km}$ [3]. Gas pipes are made of stainless steel, with the obligatory use of anticorrosive coatings and thermal insulation [3]. In order to prevent the corrosion, the principle of cathode protection is also used. The required thickness of the gas pipeline's wall is calculated by taking into account the default diameter, maximum pressure and safety factor. The pipeline diameter may vary depending on the situation and need, and the maximum permissible diameter value today is 2.5 meters [2].

\subsubsection{Gas pipeline operations}

The gas pipeline operations process begins after the extraction of the natural gas from the wells at the gas site, with the process of collecting and storing natural gas in temporary storage tanks. After the sufficient quantities of natural gas have been collected, the purification process follows [4]. At first, the groundwater, dirt and dust impurities are filtered, after which condensates and oil mixtures are separated. Subsequently, acid gases (carbon dioxide, hydrogen sulphide) are removed. It is also necessary to make nitrogen and helium separation in order to reduce transport costs. The next step is heavy hydrocarbons separation in order to ensure lean product with mainly methane in the final composition. The final step is drying of the natural gas in order to ensure appropriate dew levels. After purification process is completed, natural gas enters a compressor station to reach the required pressure for the transport through pipelines [3]. As the natural gas is in transported through gas pipeline, one or more compressor stations are needed on a route for the recompression due to the pressure drop, especially when transportation distance is long [2]. Upon arrival at a destination, the natural gas from a natural gas pipeline enters a receiving station where it passes the odorization treatment, i.e. adding the artificial odorant, to adapt to the requirements of the distribution network and to ease the detection in the event of a leakage, since the natural gas itself has no odor [4]. After this, natural gas is stored and supplied to the end users.

\subsection{FSRU terminals}

Floating storage and regasification unit (FSRU) is actually a special type of vessel that serves to convert liquefied natural gas into its gaseous state. The exploitation of this kind of terminals began in the United States in the 2000s, and thanks to its application, this technology has rapidly spread throughout the world, so the current fleet consists of 29 vessels [5]. These terminals are set up in places where the construction of a classic land terminal is impossible or economically unprofitable. Due to their characteristics, the FSRU vessels are particularly suitable for opening smaller or inaccessible markets, thus many countries that have not yet been affected by supply routes have joined the global LNG market [6]. The FSRU terminals perform the same operations as the land terminals for LNG reception. The LNG transport ships deliver liquefied natural gas, which is transshipped to the FSRU vessel. Afterwards, the 
regasification process of LNG begins, which is then odorized and distributed from the FSRU vessel to a pipeline network to reach the consumers.

\subsubsection{FSRU terminals in general}

FSRU terminals could be classified into two categories either as vessels or as offshore units [7]. The construction of a terminal is based on the classic settings of LNG shipbuilding, with additional features related to the regasification processes itself and related operations. Vessels are subject to all common international safety standards applicable to classic LNG ships, with mandatory regular inspections in the appropriate periods. In case of an offshore unit there is a further division in two classes - mobile (with propulsion) or fixed (without propulsion) [7]. An example of the offshore unit is the FSRU Toscana that is permanently located and anchored in the territorial sea of Italy [5]. Nevertheless, the classification as vessels is largely prevalent, giving the companies the flexibility and ability to exploit the vessel as an access terminal or classical LNG ship. Because of the growing demand for LNG as a propulsion fuel for today's merchant ships, the important function of the FSRU vessels is to carry out LNG bunkering operations, i.e. fuel supplies to ships [8]. This is due to the directive of the International Maritime Organization (IMO) on sulfur reduction in fuels, which is coming into force in 2020 [9]. Additional functions of an FSRU vessel include LNG discharges on smaller ships for LNG transport, road LNG tankers and specially designed containers. All FSRU vessels are adapted to specific local conditions and are subject to certain national standards and norms of a particular country on whose territory they operate. FSRU terminals in foreign terminology are also called GIFT (Gas Import Floating Terminal), LNG RV (Regasification Vessel) and Energy-Bridge ships (the name was mainly used by the El Paso energy company) [10].

\subsubsection{FSRU terminal operation processes}

Once the liquefied natural gas (LNG) is discharged to an FSRU terminal, it is necessary to carry out the regasification process before the natural gas is sent further to a supply pipeline network. The regasification system (REGAS system) is the main functional system of each FSRU terminal [11].

The regasification process begins with the supply of an LNG cargo from cargo tanks to the suction drum where regasification process commences [11]. Suction drum serves as an LNG collector just prior to the regasification process in order to ensure optimal LNG flow in the regasification system. At the same time, it also serves as an evaporated gas accumulator prior required return to the cargo tanks [7]. From the suction drum the LNG is delivered to the high-pressure LNG pumps that are in charge of supplying the LNG evaporators. The LNG evaporator is actually a heat exchanger that serves to convert LNG from liquefied to gaseous aggregate state. Thus, in the evaporator, the central process of converting from liquefied to gaseous state takes place [11]. Once it has passed through an
LNG evaporator, the natural gas is now again in its natural gaseous state. After passing through the gas quantity and delivery measuring system, the natural gas is discharged to the supply network. The floating terminal pipelines are connected to the land gas pipeline network and the gas quantities are sent directly from an FSRU terminal to the supply networks. Since the natural gas has no odor, before it is discharged into the main gas pipeline, it is artificially odorized to make it easier to determine its presence.

\section{Natural gas market outline}

In line with the increased demand, countries rich in natural gas have record export figures. Today, the largest natural gas sites are located in Russia, Qatar, Iran, Australia, United States of America, Canada, Saudi Arabia, Turkmenistan, United Arab Emirates, Venezuela, Nigeria and Norway, and these countries are the world's largest exporters [12]. Conversely, the largest importers of natural gas today are South Korea, India, China, Japan, Colombia, Bangladesh, Egypt, Turkey and the European Union countries, where France, United Kingdom, Germany and Italy are preceding [12].

\subsection{Natural gas pipeline imports}

When it comes to the import of natural gas through gas pipelines, statistical figures depict growing trends. In this case the most important figure is the total annual quantity of gas delivered. The quantity of natural gas imported through the gas pipeline is commonly measured in the $\mathrm{BCM}^{1}$ measuring units, but for a better comparison with FSRU terminals, the conversion to the MTPA $^{2}$ measuring units was necessary. Thus, in 2017, the total amount of natural gas delivered by gas pipelines was approximately 540 MTPA [12]. Despite the high capacity of LNG terminals, currently more than half of this capacity is unused, and still more natural gas is transported by gas pipelines [13]. The largest part of natural gas pipeline exports for 2017 belongs to Russia with about 160 MTPA, followed by Norway with about 80 MTPA, Canada with about 70 MTPAs, the USA with about 50 MTPA and Algeria with about 30 MTPA. The largest importers in 2017 were European countries with about 310 MTPAs, preceded by Germany with about 70 MTPA, followed by Italy with about 40 MTPA, United Kingdom with about 30 MTPA, Netherlands with about 30 MTPA and France with about 25 MTPA. Interestingly, in latter category there is also the USA with about 65 MTPA, Mexico with about 30 and China with about 30 MTPA [12]. Therefore, the major gas pipeline routes are Russia to EU countries, Norway to EU countries, Canada to the USA, the USA to Mexico, and Algeria to Spain [14].

\footnotetext{
BCM (billion cubic metres) - denotes a measuring unit for the quantity of imported natural gas.

2 MTPA (million tons per annum) - denotes a measuring unit for the quantity of imported LNG.
} 


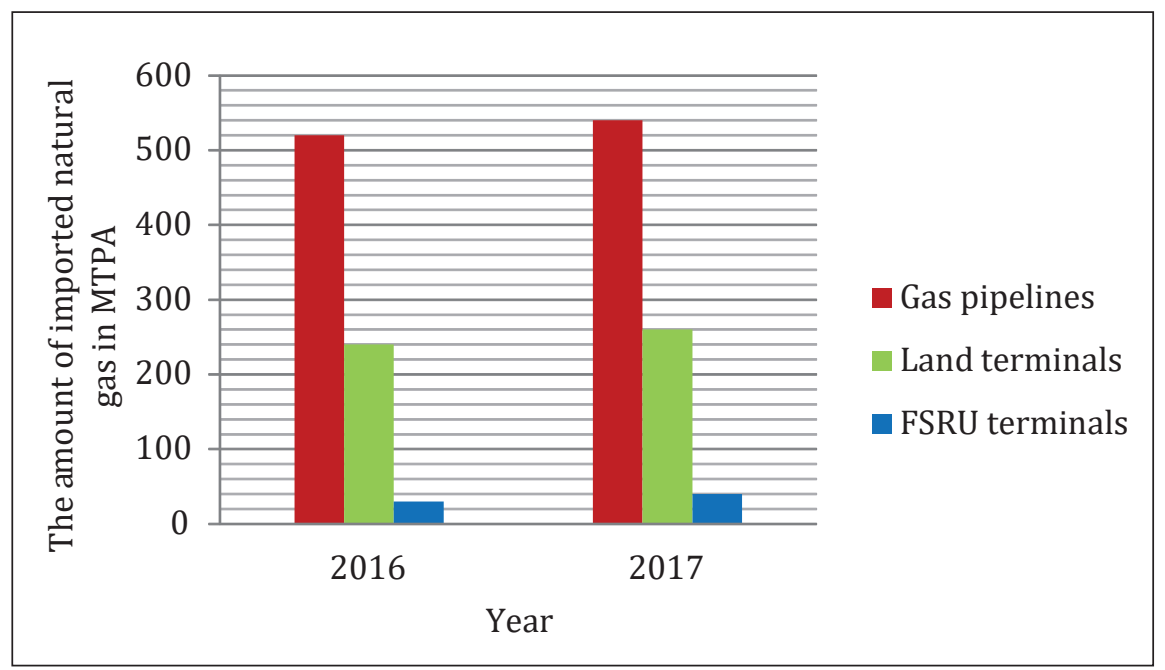

Figure 1 Comparison of the quantity of imported natural gas Source: Authors

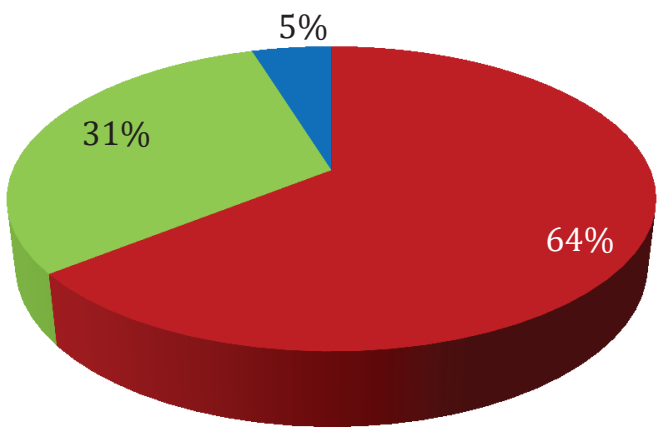

Gas pipelines (540 MTPA)

Land terminals (260 MTPA)

- FSRU terminals (40 MTPA)

Figure 2 Percentage share of natural gas imports in 2017 Source: Authors

Figure 1 shows the comparison of the amount of imported natural gas in 2016 and 2017. There is a noticeable increase in all three types of imports. Thus, the import by gas pipelines have increased from 520 to 540 MTPA, by land LNG terminals from 240 to 260 MTPA, and by FSRU terminals from 30 to 40 MTPA.

Figure 2 shows a percentage share for each of the three types of natural gas import in 2017. A similar situation was in 2016.

As already mentioned above, gas pipelines represent the convincingly cheapest form of natural gas transport, cheaper than the FSRU and land terminals. The average cost per kilometer of land gas pipeline is between $\$ 1$ and $\$ 3$ million, and underwater between $\$ 2$ and $\$ 4$ million [7]. At first glance, it may seem like a fairly high price when it is taken into account that the required length of the gas pipeline is usually several hundred kilometers, but after the capital expenses of the construction itself, operational exploitation expenses and maintenance expenses are lower than in the case of land or FSRU terminals [1]. These expenses are, of course, largely dependent on the total length of the gas pipeline and type of gas pipeline (land/underwater), thus there is a broad range of possible expenses, but when all is summed up the average amounts to range from $\$ 2$ to $\$ 5$ million a year. In addition, the whole process which natural gas has to pass before being transported by gas pipelines is simpler and cost effective, especially in comparison with sea LNG transport where it is necessary to perform liquefaction and regasification. Also, unlike the terminal, there is the possibility of constant uninterrupted natural gas supply.

\subsection{FSRU imports}

Currently, 35 countries have LNG import terminals [5]. This includes land and FSRU terminals, so they are best studied in correlation with each other. MTPA units commonly measure the amount of imported LNG. World regasification capacities continued to move upwards in the early 2018 with the amount of 851 MTPA, which is an increase of 56 MTPA relative to the 795 MTPA in 2017 [5]. Also, from the regasification capacities currently in development, it is evident that by the end of 2019 approximately 40 additional MTPA will be operational, mostly in China and India. Of the total 851 MTPA, 767 belong to land terminals, while 84 MTPA is imported through FSRU terminals [5]. The total utilization percentage of import terminals was around $35 \%$, which means that annually 300 


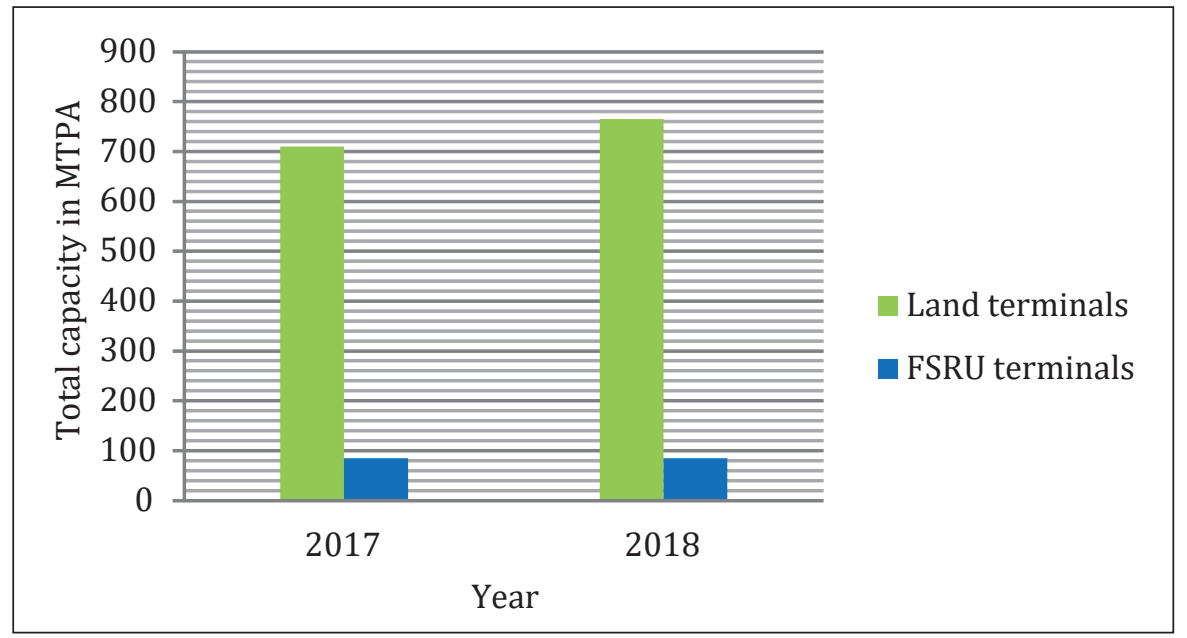

Figure 3 Comparison of total capacity of importing LNG terminals Source: Authors

MTPA of natural gas is imported through land and FSRU terminals [5]. The utilization of total capacity of land import terminals (data for 2017) is about 34\% (260 MTPAs imported per year), while the total capacity utilization of the FSRU terminals is $47 \%$ (40 MTPAs imported per year) [12]. The average existing regasification capacities are 7.8 MTPA for land terminals, and 4.2 MTPA for FSRU terminals [5]. The largest exporter of LNG in 2017 was Qatar with about 85 MTPA and then Australia with about 65 MTPA, followed by Malaysia with about 25 MTPA and Nigeria with about 20 MTPAs, while convincingly the largest importer was Japan with about 85 MTPA, followed by China with about 40 MTPA and then South Korea with about 40 MTPA and India with about 20 MTPA [12].

Figure 3 shows an increase in the total import capacity of LNG terminals in 2018 compared to the previous year.

In terms of prices and expenses, FSRU terminals are cheaper than land terminals, but more expensive than natural gas pipelines. Capital expenses (CAPEX) of the FSRU terminals with new FSRU shipbuilding are around \$300-500 million, depending on the size of the ship and the ancillary port infrastructure (e.g. a breakwater) that needs to be built [7]. The rough assessment is that capital expenses for the construction of the FSRU terminal are about $\$ 80$ per ton of regasification capacity. As for the duration of construction, the new FSRU vessel is usually delivered within 27 to 36 months, and the conversion of conventional ships for the transport of LNG to FSRU vessels is even faster and lasts between 18 and 24 months [7]. Operational expenses (OPEX) of FSRU vessels range in between $\$ 20,000$ and $\$ 45,000$ a day [7]. The general assumption is that these expenses per year are about 1-3\% of total capital expenses [15].

\subsection{Price comparison}

It is evident that natural gas transport by pipelines is a low-cost option in comparison with shipping. For this reason there is a difference in purchase prices. It is im- portant to note that prices share volatile outlook as other commodities. However, an average price amount for each of these two types of import can be presented. The prices of natural gas transported by pipelines are ranging on average from 2.50 to $8.50 \$ / \mathrm{Mbtu}^{3}$, while the prices of natural gas transported as LNG and delivered at terminals are ranging on average from about 6.50 to 12.50 \$/Mbtu [16]. As already mentioned above, the natural gas market is dynamic and prices are subject to volatility.

\subsection{Future forecasts}

The growing global demand encourages supply and shifts focus from other fossil fuels. Large exporters such are Russia, Qatar and the USA will surely retain this primacy. Qatar is the main exporter of LNG and the business volume of this country mainly relies on receiving terminals (land or FSRU). The United States also mostly exports to receiving terminals, but also partly to gas pipelines to Mexico. Japan, China and South Korea growth and development remains positive, so it is expected that they remain largest importers through LNG terminals. An interesting situation is in North America, where the northern federal states of the USA import large quantities of natural gas from Canada, while the southern federal states of the USA export a large amount through gas pipelines to Mexico, and by ships to transoceanic countries. This is precisely the main reason explaining the curiosity why the USA with large export also participates in the import of natural gas. Energy and shipping sector of the USA works with government to overturn Jones Act from 1920s where only US build and US flagged vessels are allowed to do domestic transports. As there are only few old vessels built in the USA still active today, it is impossible to organize transport by vessels from the south coast to the northern states without changing the Jones

\footnotetext{
\$/Mbtu (US dollar per one million BTUs) - BTU or British thermal unit is a traditional heat unit, defined as the amount of heat needed to raise the temperature of one gram of water to one degree Celsius.
} 
Act. In the mean time the USA will remain focused on the LNG exports and offset imports by having global influence on prices. Russia remains the largest exporter through gas pipelines, mostly to European Union countries. However, for various political reasons and imposed sanctions, the EU has progressively altered focus on diversification of natural gas supply, and with the construction of LNG terminals, such as in Lithuania, seeks to reduce dependence on Russian gas and consequently reduce the import of natural gas, despite the fact that this gas is cheaper than alternative variants of imports via LNG terminals. Therefore, the European Union could turn more to imports through LNG terminals in the forthcoming period, as evidenced by the completed and operational project in Lithuania, and by the start of project planning in Croatia. Accordingly, Russia, in order to continue to export its large quantities of natural gas, could turn to other markets, and China certainly represents the great potential. China is a large natural gas importer via LNG terminals, but the benefits of gas pipelines in terms of better financial picture have largely begun to reflect on the connection by gas pipelines to the Russian network. However, the problem is the fact that the Russian gas pipeline on its way to the large populated Chinese places has to go through rather large areas of uninhabited and deserted territories, which can cause problems with underutilization, maintenance and excessive initial capital expenses. Russian Novatek is therefore focused on delivery of LNG through north passage by vessels as alternative to building vast distances of pipelines. Also, Russia is setting up its first FSRU terminal in Kaliningrad, which may come as a curiosity, but is in fact a necessity, to bypass pipeline gas deliveries through Lithuania in case transit is ever

Table 1 LNG terminals under construction

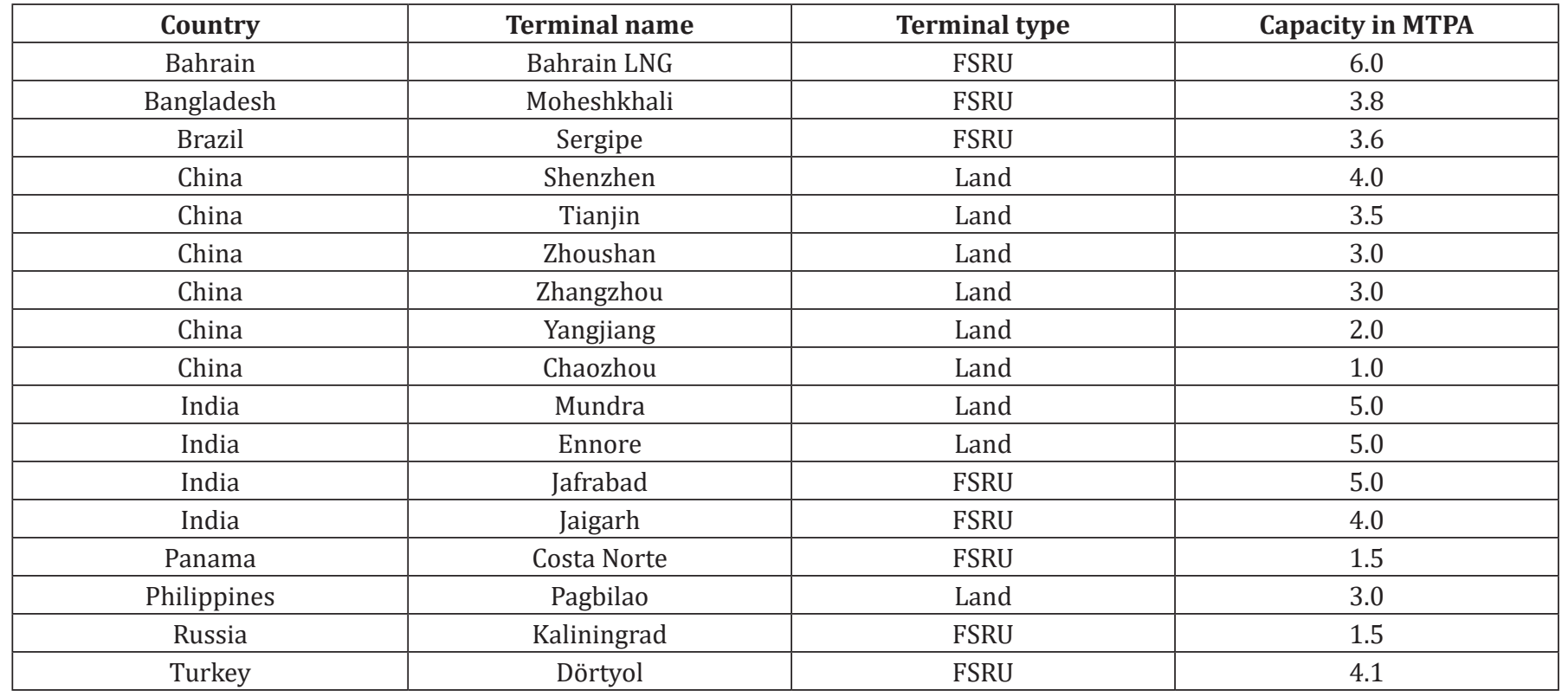

Source: Authors

Table 2 New gas pipeline projects

\begin{tabular}{|c|c|c|}
\hline Gas pipeline & Route & Status \\
\hline Alaska Gas & SAD - Canada & In plan \\
\hline Altai & Russia - China & In development \\
\hline Baltic Connector & Finland - Estonia & In plan \\
\hline Baltic-Pipe & Norway - Poland & In plan \\
\hline GALSI & Algeria - Italy & In development \\
\hline IP Gas & Iran - Pakistan & In development \\
\hline Southern Gas Corridor & Middle East - South East EU & In plan \\
\hline Trans-Caribbean & Venezuela - Panama & In plan \\
\hline Trans-Afghanistan & Turkmenistan - India & In plan \\
\hline Trans-Caspian & Turkmenistan - Turkey & In plan \\
\hline White Stream & Nigeria - Algeria & Georgia - Romania \\
\hline
\end{tabular}


disrupted. Kaliningrad is a Russian exclave on the Baltic Sea, and is therefore isolated from the Russian mainland, so this project will greatly increase its energy security.

Many land and FSRU terminals are at the final stages of the development, and will be put into operation in the very near future, which will further increase the total terminal capacity and the quantity of imported LNG. The largest number of new terminal constructions is related primarily to the already traditionally large natural gas importers, China and India. The Table 1 gives a list of LNG terminals close to the start of the exploitation.

In addition, there are also projects for some completely new gas pipelines, as well as the expansion of the existing network, some of which have already begun with the development. In Table 2 there is an overview of gas pipeline projects.

\section{Conclusion}

This paper gives an overview of natural gas imports through natural gas pipelines and floating terminals. Even though import price of the natural gas through pipelines is lower, geographical challenges are driving demand for LNG. Capital cost of building pipelines for large distances where various political and geological challenges exist is the main reason why alternative to pipelines exist. Natural gas extraction sites are usually located far away from the consumer, so LNG shipping offers a viable alternative to pipeline operations. LNG imports are more expensive due to necessity of land or floating terminals; however secluded extraction sites can be used for distribution and delivery. It is easier to control the price of imported natural gas when only fixed pipeline system is in use. This is also one of the reasons why coastal countries continue to develop import terminals, as in that case any cargo in the world can be imported for a desired price. Through gas pipelines the natural gas is transported in its natural gaseous state, while by tanker ships it is transported in liquefied state as liquefied natural gas (LNG), because it is 600 times smaller in volume than in the gaseous state. Such ships deliver cargo to import terminals that can be either land or floating type. The FSRU ship's technology is specific primarily for the flexibility and cost-effectiveness of these ships. Countries that for various reasons are not able to import natural gas over land gas pipelines, or want to diversify their supply directions, decide on sea imports. In many situations, the construction of an importing land LNG terminal is not possible or financially viable and that's where the FSRU vessels are feasible alternative. Lower construction costs, especially daily exploitation and maintenance costs, and the possibility of constant uninterrupted gas supply, makes natural gas pipelines a preferred option where potential for development exists. However, development of pipelines can take years and is not a viable option for vast distances or scattered consumers; therefore LNG import terminals will remain strong alternative option that can ensure diversification and supply to consumers that are far from extrac- tion sites. Following the global demand for alternative and sustainable fossil fuel, natural gas will remain strong energy commodity and upward trends of exports and imports can be expected through both pipeline networks and import terminals.

\section{References}

[1] Kavalov, B., Petric H., Georgakaki, A., (2009), Liqueified Natural Gas for Europe: Some Important Issues for Consideration, European Commission, Joint Research Centre Brussels, Belgium, pp. 7-29.

[2] Rudarsko-geološko-naftni fakultet, Transport $i$ skladištenje prirodnog plina, Zagreb, 09.11.2010, URL: https://rudar. rgn.hr/ dkarasal/NIDS/GOSPODARENJE\%20PLINOVIMA\%201/GP1-5\%20Transport\%20i\%20skladistenje\%20 prirodnog\%20plina.pdf (20.11.2018)

[3] Folga, S.M., (2007), Natural Gas Pipeline Technology Overview, Argonne National Laboratory, Lemont, IL, USA, pp. 12-60.

[4] Brown M., Bryant N., Haynes D., (2008), Study on LNG Quality Issues, a study for the European Commission - JRC Institute for Energy, Advantica Ltd., Loughborough, The UK, pp. 10-33.

[5] International Gas Union, IGU World LNG Report - 2018 Edition, 01.09.2018, URL:https://www.igu.org/sites/default/files/node-document-field_file/IGU_LNG_2018_0.pdf (05.11.2018)

[6] Said, M., Meijerink, J., (2004), LNG Import Terminals: „Offshore vs Onshore" - A Site and Concept Screening Methodology, Shell Global Solutions International B.V., pp. 1-13.

[7] Songhurst, B., (2017), The Outlook for Floating Storage and Regasification Units (FSRUS), The Oxford Institute for Energy Studies, Oxford, The UK, pp. 3-27.

[8] Giranza, M.J., Bergmann, A., (2018), An Economic Evaluation of Onshore and Floating Liquefied Natural Gas Receiving Terminals: the Case Study of Indonesia, IOP Conference Series: Earth and Environmental Science, pp. 2-8.

[9] International Maritime Organization, Sulphur 2020 - Cutting Sulphur Oxide Emissions, 17.01.2019, URL: http://www. imo.org/en/MediaCentre/HotTopics/Pages/Sulphur-2020. aspx (15.03.2019)

[10] Höegh LNG, Fleet Information, 01.10.2018, URL: http:// www.hoeghlng.com/Pages/Fleet.aspx (10.12.2018)

[11] Hochung, K., JungHan, L., (2005), Design and Construction of LNG Regasification Vessel, Gastech, Bilbao, Spain, pp. 3-10.

[12] BP, BP Statistical Review of World Energy, 04.06.2018, URL: https://www.bp.com/content/dam/bp/en/corporate/ pdf/energy-economics/statistical-review/bp-stats-review2018-full-report.pdf (10.11.2018)

[13] Paltsev, S., (2015), Economics and Geopolitics of Natural Gas: Pipelines versus $L N G$, Massachusetts Institute of Technology, Cambridge, MA, USA, pp. 1-5.

[14] Eurogas, Eurogas Statistical Report: 2015, 01.07.2016, URL: https://eurogas.org/flipbooks/statistical-report-2015/ (10.12.2018)

[15] Bros, T., (2018), Quarterly Gas Review: Analysis of Prices and Recent Events, The Oxford Institute for Energy Studies, Oxford, The UK, pp. 2-20.

[16] Oxford Energy, Quarterly Gas Review, 01.06.2018, URL: https://www.oxfordenergy.org/wpcms/wp-content/uploads/2018/06/Quarterly-Gas-Review-2.pdf (10.11.2018) 